\title{
Testimonios
}

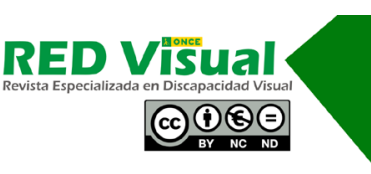

Recepción: 24-05-2021 Aceptación: 26-05-2021

\section{La covid, mi sordoceguera y yo}

\author{
R. Alba Martín
}

iHola! Ante todo, nos presentamos. A una de nosotras creo que ya la conocéis todo el mundo, ya que se trata de la covid, por lo que solo queda presentarme a mí misma: me llamo Raquel Alba, soy una mujer sordociega de treinta y tantos, afiliada a la ONCE, usuaria de perro-guía, mi perrita Halima, y de implante coclear (lo uso desde mi infancia, debido a que no cuento con ningún resto auditivo; es un dispositivo que me permite oír bastante, aunque no de la misma manera que las personas oyentes). Vivo con mi marido y mi hija en un piso madrileño desde que vinimos por mi trabajo actual como asesora de la Unidad Técnica de Sordoceguera. Me comunico tanto en lengua oral (gracias a la combinación del implante coclear y la lectura labial, puesto que dispongo de unos poquitos restos visuales muy bien aprovechados en el centro del campo visual) como en lengua de signos (táctil la mayoría de las veces).

Ahora sí, ¿cómo viví esta época que nos está afectando a todos? Personalmente, me siento afortunada, porque vivo con mi familia en nuestro piso y también porque manejamos bastante bien las nuevas tecnologías para gestiones cotidianas. Si viviera sola, sería otra historia, ya que tendría que apañarme por mi cuenta con todo lo que necesitara: comprar la comida, las medicinas, las mascarillas, acudir a las citas médicas, etc.

Las nuevas tecnologías se convirtieron en nuestro mejor compañero: pudimos hacer muchas gestiones, como aplazar las citas médicas, realizar transferencias, papeleos respecto al ERTE que viví, conseguir mascarillas, contactar con nuestras familias y amistades, sacar partido a nuestra creatividad (como hacer un cortometraje familiar y un cuento), compartir y recibir información útil sobre las medidas higiénicas y de seguridad..., pero también la lúdica y deportiva, para sentirnos mejor al estar confinados durante el estado de alarma. 
Por ello, fue y sigue siendo fundamental que todos los dispositivos y toda la información a la cual accedemos mediante ellos sean accesibles y respondan a cada tipo de necesidades. No siempre ha sido así. Sin embargo, gracias al esfuerzo que estamos realizando desde todos los sectores, como, por ejemplo, desde la ONCE (especialmente el CTI y el ClubONCE) y desde el movimiento asociativo con entidades como el Cermi y Fasocide (Federación de Asociaciones de personas sordociegas de España) estamos viviendo un cambio, y cada vez hay más accesibilidad. Aprovecho esta ocasión para decirles: iMuchas gracias! Pude llevar a la práctica consejos para mi bienestar emocional, aprender alguna receta y disfrutar de manualidades con mi hija gracias al ClubONCE, recibir información actualizada relacionadas con las medidas de seguridad e higiene desde Asocide Comunidad de Madrid, acceder a algunos webinarios del ciclo No estás sola de la Fundación Cermi Mujeres, recibir mensajes por WhatsApp de mi profesional especialista en sordoceguera para ver si tenía alguna necesidad para poderme apoyar y ayudar, etc.

Lo peor para mí durante esta pandemia fueron las primeras salidas a la calle. Reconozco que tenemos la suerte de ser una familia sana y joven, por lo que seguro que estuvimos menos preocupados y ansiosos que mucha gente. Sin embargo, lo viví de una manera nada agradable, ya que... ¿cómo puedo comunicarme con la gente si no les puedo tocar ni leerles los labios si llevan mascarilla? ¿Cómo puedo orientarme y acceder a diferentes objetos sin tocar, como en un supermercado, por ejemplo?

La mascarilla es una barrera para bien y para mal. Reconozco que antes de que fuera obligatorio su uso, estaba más nerviosa al salir a la calle para pasear a Halima, por ejemplo, ya que no podía controlar si alguien se acercaba «demasiado». Después, una vez todos con nuestras mascarillas, me sentí un poco más tranquila y aliviada al no tener que vigilar todo el tiempo por todos lados con mis pocos restos visuales. Otra cosa es la comunicación. Para ello recurrí muchísimo a mi móvil para usar diferentes aplicaciones como ListenAll o Transcripción Instantánea, que me permiten acercar el móvil a la persona sin que se quite su mascarilla; lo que la persona dice sale por escrito, y así puedo leerlo y responderles. Siempre después de explicarles por qué y cómo se hace, por supuesto. Funciona sobre todo en entornos no muy ruidosos.

También tenía mucho miedo cuando veía a mi perrita que quería olfatear todo (y quizá rozar con su hocico cualquier cosa que pillara por el suelo). Por eso tenía que tensar un poco la correa para no permitirle hacerlo siempre. Al volver a casa, le limpiaba las patitas con agua y jabón. No sé si funcionaba, pero al menos nos sentíamos 
más tranquilos... Hablando de Halima, también recuerdo una pregunta que me hice en los primeros días de la pandemia: ¿Halima también puede ser receptora de la covid y contagiar a los demás, tanto a los perros como a las personas? También teníamos que pedir a la gente que no la acariciara ni la saludara, aunque no llevara el arnés puesto. Para Halima fue un cambio duro, pero creo que, con toda nuestra atención y nuestros mimos, lo llevó muy bien.

Respecto a nuestra hija, cada vez que salíamos de paseo, cuando ya estaba permitido, recuerdo que muchas veces pensé para mis adentros: isocorro, que lo toca todo, pero TODO! Es pequeña y es normal que tenga ganas de explorar: coge un palo para lanzárselo a Halima, agarra unos postes para subirse a una valla y luego caminar haciendo equilibrios, etc. Procuraba no ponerme histérica, pero le explicamos que era fundamental no tocarse la cara mientras estábamos en la calle y le pedía que se limpiara las manos con frecuencia. Me siento orgullosa de mi niña, ya que, siendo tan pequeña, lo acepta todo muy bien. Durante el confinamiento, se las ingeniaba e inventaba mil juegos para disfrutarlos en familia. Lo que más le costaba (y a nosotros) era hacer deberes «aburridos» un ratito cada día sin tener a sus compañeros al lado.

Cambiando de tema: hablaré del tacto. Poco a poco, aprendí a usar el tacto de otra manera, puesto que, para mí, como para todo el colectivo de personas con sordoceguera, sigue siendo esencial. Ir bien equipada de gel hidroalcohólico me permitía tocar objetos cuando era necesario, como las barandillas, los botones del ascensor, las máquinas, etc.

Eso sí, en comparación con mi marido, salí muy pocas veces a la calle. Mi marido era el que se encargaba de comprar la comida, ir a la farmacia... Cuando finalizó mi ERTE y me tocó volver al trabajo, aprendí a tomármelo bien y a tener precaución. Tenía que coger el metro y el autobús, pero afortunadamente hasta hoy todo ha ido bien.

También me gustaría contaros que, recientemente, tuve que ser ingresada urgentemente por otros motivos de salud, y la verdad es que la situación es muy distinta a la que vivimos antes de la existencia del coronavirus. Como me sentía débil, no llevaba el implante coclear puesto y tampoco tenía a mi lado mi móvil, así que cuando me hacían pruebas tenía que estar sola y me sentía perdida y, a veces, también desinformada, impotente y discriminada. Me dije a mi misma: menos mal que esto no es duradero... Ahora que ya me encuentro bien, me pregunto: ¿qué pasa con las personas sordociegas que tienen que estar ingresadas durante un tiempo prolongado?

Alba, R. (2021). La covid, mi sordoceguera y yo. RED Visual: Revista Especializada en Discapacidad Visual, 77, 337-340. https://doi.org/10.53094/RDNP1083. 
Aunque todos siempre lo hacemos con la mejor intención, estas situaciones no podemos permitir que se repitan. Es verdad que todos estamos trabajando para evitarlas, aunque todavía hay un largo camino por recorrer. Para ello, realmente es necesario que cada uno aporte su granito, como, por ejemplo, avisar a la ONCE al detectar alguna situación similar a esta a través del apartado Defiende tus derechos del ClubONCE.

Finalmente, me gustaría cerrar mi experiencia personal contando que, después de haber pasado malos ratos, ahora, en la nueva normalidad, descubrimos que, más que nunca, realmente la unión nos hace fuertes: la solidaridad, el compañerismo, el apoyo, el voluntariado... Personalmente, pude acompañar telefónicamente mediante videollamada o WhatsApp a varias personas sordociegas. También fui receptora de este apoyo de los voluntarios - como los de la ONCE, por ejemplo- para cuando necesitaba salir a hacer deporte caminando a un ritmo rápido. Es maravilloso este sentimiento de estar unidos.

\section{Raquel Alba Martín}

